Doi: $10.24234 / \mathrm{se} .2020 .2 .2 .235$

\title{
TEACHING BRAILLE LITERACY TO BLIND PRIMARY SCHOOLCHILDREN AND THOSE WITH RESIDUAL VISION
}

\author{
AUTHORS' DATA: \\ Sona Davtyan, $\mathrm{PhD}$ in Education, Associated professor \\ Chair of Special pedagogy and psychology, Khachatur Abovyan Armenian State Pedagogical University, \\ Armenia \\ University lecturer \\ Contacts: $\underline{\text { d-sona@mail.ru }}$
}

Lilit Avagyan, MA in Special Pedagogy (Pedagogy for children with visual disorders)

Siamanto Basic School No.162, Armenia

Student assistant

Contacts: lilitavagyan1997@mail.ru

\begin{abstract}
Nowadays one of the main issues of pedagogy is teaching to primary school children who are blind and those with residual vision. Among those schoolchildren writing disorders are quite common and have a negative effect on their learning progress. The quality and acquisition of school curriculum slows down, and in general negatively affects the learning process of these children. The relevance of the study depends on the fact that sufficient methods, approaches related to teaching Braille literacy have not yet been thoroughly studied and developed.There are insufficient typhlotechnical, typhographic techniques to help promote literacy through the Braille system.
\end{abstract}

The study of the above-mentioned and other similar issues will help to fully implement the Braille system thus improving the writing abilities of children with visual impairments.

Key words: primary school blind children, primary schoolchildren with residual vision, Braille system, writing abilities, difficulties, assessment, assessment form. 


\section{INTRODUCTION}

Braille is a tactile writing system used by people who are visually impaired. It is traditionally written with embossed paper. Braille users can read computer screens and other electronic supports using refreshable braille displays. They can write braille with the original slate and stylus or type it on a braille writer, such as a portable braille notetaker or computer that prints with a braille embosser (Damon, 2012). Braille literacy is a social-justice issue. Early Braille education is crucial to literacy, education and employment among the blind (American Foundation for the Blind, 2018)

Teaching writing in Braille requires special, purposeful approaches (Hudson, 2012). The first and at the same time the most difficult task to begin the process of learning literacy is to master the technical side of the learning process (Hermida \& Rodríguez, 1996). Based on the analysis of the results of a number of studies in the related field, it is possible to state that while the absence of visual perception the technical side of the Braille writing learning process can be represented by the following actions:

- tactile perception of convex-dot letters;

- recognition of the latter and recognition;

- reproduction of the phonetic image of the word;

- perception of the word and letters(Seim, Quigley\& Starner, 2014; Avramidis\& Norwich, 2010; Bardin \& Lewis, 2008).

It is worth mentioning that the fact that this problem is theoretically and practically insufficiently elaborated and developed complicates the issues of teaching means, approaches, pedagogical work of the reading and writing process through the Braille system among blind primary school children(Seim, Quigley\& Starner, 2014). Therefore, we believe that the study of selection and coordination of special tools for the development of reading and writing skills of children with visual impairments will contribute to the favorable development of this work.

It's obvious that the loss of vision negatively affects the perception of the outside world from all perspectives. Vision or eyesight is a true gift from nature. Due to it, it is possible to perceive the outside world with all its colors. More than $80 \%$ information people get through eyes (Bardin \& Lewis, 2008; Avramidis\& Norwich, 2010).

While reflecting to writing it is very important to state that it is the hardest type of verbal activity. It requires special and targeted learning in order to acquire and master it. And for children 
with visual impairments it becomes more difficult to take up the writing (Seim, Quigley, \&Starner, 2014). Among children with visual impairment and schoolchildren poorly performing at schools there is a group that has sustained difficulties in acquiring literacy even if they possess ordinary abilities. They are either not literate at all or read and write with typical mistakes. Visual impairments cause such personal characteristics as loneliness, selfishness, distrust of their own power and so on. These children experience difficulties in micro environment (Andjelkovic, 2017).

The analysis of the abovementioned methodological literature on the problem related to the statement of the current study shows that the problem of teaching the writing to visually impaired children with Braille system is considered pedagogically important. Solving many of issues related to this quite complicated process will help the growing generation become more literate and educated. The significance of this problem is mainly viewed in two aspects:

- the use of teaching with Braille system methods in N. Tigranyan special school for children with visual impairments in Yerevan;

- pedagogical difficulties that are faced during the educational activities among young blind schoolchildren and those with residual visual in school.

Therefore multiple analysis of this issue, its approaches, teaching with braille methods, selection, coordination of pedagogical methods, relevant typhlotechnical measures and conditions are considered important grounds for solving this problem.

The study of comprehensive approaches to learn writing with the braille system among young blind schoolchildren and those with residual vision, the analysis of theoretical approaches, the clarification of theoretical approaches and pedagogical conditions showed that in scientificmethodical literature it is viewed from different angles (Davtyan, 2018; Seim, Quigley, \&Starner, 2014;Andjelkovic, 2017).

The first point is viewed as a purpose of studying unfavorable conditions where teaching the writing and developing writing skills to visually impaired children with Braille system happen. First of all it is the insufficient quantity of equipment, typewriters, books and so on. The next point is viewed as an insufficient development of schoolchildren fine motor skills, which stands as a barrier for organizing teaching of the writing (Davtyan, 2018). And because of this proper selection and application of appropriate methods and measures during the teaching process with Braille system writing becomes significant. 
Taking into account the above mentioned, the main aim of the current study is to choose and coordinate some practical measures of schoolchildren with visual impairment poorly performing at school.

First of all it was planned to:

- study the difficulties of the writing with Braille system in N. Tigranyan special school for children with visual impairments in Yerevan;

- develop a portfolio for each child in order to study the learning abilities of the writing with Braille system.

Within this scope the following problems of the study are highlighted:

1. To study the relevance of the problem in modern scientific literature.

2. To examine the abilities of the blind preliminary schoolchildren and those with residual vision while teaching the writing with Braille system in school.

3. To coordinate some measures and their usage that support the development of the abilities of blind preliminary schoolchildren and those with residual vision during the use of Braille system and identify the special conditions for applying them.

\section{METHOD AND PROCEDURE}

In order to study the features of the writing with Braille system of blind primary schoolchildren and those with residual vision, the practical usage of the writing with Braille system was first investigated. 10 teachers from N. Tigranyan special school for children with visual impairments in Yerevan (capital of Armenia) participated in this research. The average age of the respondents was 33 to 55 years, and the work experience with children with visual disorders was 10 to 25 years.

The open-ended questionnaire was developed in order to understand the following aspects

of the problem. The questionnaire included a number of questions, which were grouped in the following directions:

- The views and experiences of teachers about the current issue were extremely important within the scope of this study. They give importance to the necessity of using special methods and conditions for supporting the writing with Braille system of children who are blind and have residual vision. They consider the difficulties they meet during the learning process, whether they use appropriate tyflotechnical means. 
- Reflection on Braille system for teaching primary school blind children or those with residual vision (what methods and tools are used in learning Braille, what problems they encounter in organizing the learning process, etc.).

During questioning the teachers, we tried to find out the stages of learning the writing.

\section{RESULTS AND DISCUSSION}

While analyzing the results of the data, it was obvious that the teachers mentioned the methods and measures they use to teach the writing with Braille methods that support to form the writing process. We also have tried to find out the difficulties they met while organizing the writing process with Braille system.

There were different answers like "the shortage of Braille textbooks and writing equipment", "the level of physical readiness" and so on. So, the answers to our questions show that the majority of teachers think there is no corresponding scientific-methodical literature for Armenian children, that is the reason they can't use objective methods such as exercises, games. So they use their own methods.

Thus, it became clear from the study that the majority of teachers point out the necessity of teaching writing to visually impaired children with Braille system. It is important to implement while they are primary schoolchildren. However, on the other hand the measures and methods can't be used in practice because of the lack of relevant scientific-methodical literature. So there is a need to form and develop, to choose and coordinate the writing with Braille system.

Based on the above mentioned it is necessary to study the teaching process itself in the primary school where Braille system is used during the lessons. At the same time, it was very crucial for us to understand how much ready the children were to perceive and imitate this quite complicated system.

In order to explore deeply the abilities of teaching and learning to the primary schoolchildren who are blind and have residual vision with Braille system the assessment form was elaborated to measure the study preparedness among these children (Table 1).

Primary school children who are blind or have residual vision were selected for the participation based on the following two criteria: primary school age and already available knowledge in Braille system ( 2 girls and 4 boys). While using this form we have an aim to find 
out the following abilities children have and difficulties they experience while studying with Braille system:

- orientation abilities in micro area (in exercise book, in typewriter and its gaps);

- the abilities to use stylus;

- the right placement of typewriter to the Braille exercise book;

- to write point combination (letters, numbers, punctuation marks);

- the abilities to copy out (with one hand, with two hands);

- the abilities to find mistakes and correct them.

The assessment has been conducted in N. Tigranyan special school for children with visual impairments in Yerevan during 4 months (every day 1 lesson with the duration of 40 minutes).

Table1. Study preparedness assessment form for blind primary school children or those with residual vision

\begin{tabular}{|c|c|c|}
\hline \multicolumn{3}{|c|}{$\begin{array}{c}\text { Study preparedeness assessment form for primary school children } \\
\text { who are blind and have residual vision }\end{array}$} \\
\hline \multicolumn{3}{|c|}{$\begin{array}{l}\text { Child's First Name, Family Name and Name of } \\
\text { father }\end{array}$} \\
\hline Tests & $\begin{array}{c}1-5 \\
\text { points }\end{array}$ & Notes \\
\hline \multicolumn{3}{|c|}{ Readiness to use Tiflotechnical (vision related techniques) measures } \\
\hline \multicolumn{3}{|l|}{ 1. Vertical position near the seat } \\
\hline \multicolumn{3}{|l|}{ 2.Ability to use Braille typwriter correctly } \\
\hline \multicolumn{3}{|l|}{ 3. Proper installation to typewriter braille } \\
\hline \multicolumn{3}{|c|}{ Motor skills } \\
\hline \multicolumn{3}{|l|}{$\begin{array}{l}\text { 1. Point combinations (letters, numbers, } \\
\text { punctuation marks) }\end{array}$} \\
\hline \multicolumn{3}{|l|}{ 2.Copying abilities (with both hands) } \\
\hline \multicolumn{3}{|l|}{ 3.Ability to find mistakes and correct them } \\
\hline \multicolumn{3}{|l|}{ Ability to master writing skills } \\
\hline \multicolumn{3}{|l|}{ 1. Letter omission } \\
\hline 2. Words omission & & \\
\hline
\end{tabular}




\begin{tabular}{|l|l|l|}
\hline 3. Gap and letters omission & & \\
\hline 4.Understanding lines & & \\
\hline 5. Understanding gaps and points & & \\
\hline 6. Understanding the beginning of a word & & \\
\hline
\end{tabular}

The use of the following form gave us an opportunity to find out the features, difficulties, readiness of using tyflotechnical measures, the development level of fine motor skills of primary schoolchildren who are blind or have residual vision while learning to write using Braille system.

The results indicate how well preliminary schoolchildren who are blind or have residual vision understand the writing with Braille system. As it can be seen in the "Study preparedness assessment form for preliminary school children who are blind and have residual vision" mastering the writing with Braille system, as well as level of the abilities was rated from 1 to 5 points. "5 points" are given to children with no mistakes, "4 points" in case of occasional mistakes, "3 points" in case of multiple mistakes (points, lines, cells, point composition of combinations and other confusions). In case of incomplete work or work done with support and assistance only "2 points" are given. When child refuses to participate in any kind of work than "1 point" is given.

We have taken an individual approach in assessing the children within the framework of this study. The age of children (6-7years old), individual abilities, features of motor skills, degree of visual acuity, secondary disorders are taken into account.

During the study it became clear that primary schoolchildren who are blind and have residual vision while using Braille system make various mistakes, faults, omissions. These schoolchildren who are blind and have residual vision have difficulties connected with the space orientation and quality of educational activities. This was also stated by Davtyan (2018) and Andjelkovic (2017). The following features are typical for those children:

- a low level of appreciation for the overall picture;

- condition of complete and partial perception of plot images;

- inability to differentiate the primary from the secondary;

- a low level of objects recognition;

- a low level of eye-hand coordination;

- unable to recall the letters;

- inability to distinguish numbers, letters and their elements; 
- insufficient visual imagery;

- inability to distinguish elements of similar objects.

From our study it was clear that primary schoolchildren are interested in studying the writing with Braille method, however there were several difficulties with spatial orientation especially with micro spatial orientation, fine motor skills and tangible, visual perception. They had difficulties in finding educational stuff on the table, differentiating some terms like right, left, up, down. Those difficulties were among the works of blind children (making omissions, adding extra punctuation points, leaving gaps, confusing lines and so on).

Two of the children participating in the study, had difficulties in placing the typewriter to Braille exercise book, using stylus correctly. Blind children were also characterized by abnormal posture. It is important also to state, that primary schoolchildren who are blind and have residual vision have difficulties in mobility, balancing, coordination, space orientation, also touching inability, incomplete perception of characters. These things reduce the pace of acquiring the writing with Braille system and act as negative factors in learning process of the child. During the study only one of the schoolchildren didn't make serious omissions, however, it is obvious that the assessment work needs to be continued to be able to state more validated and trustworthy results (Seim, Quigley, \&Starner, 2014).

It's necessary to mention that at school while educational process a lot of work is being done to design the writing of these children. While organizing the writing with Braille system a great attention is paid to the above mentioned problems. Especially the attention of schoolchildren who are blind and have residual vision is still involuntary and not focused so they find it difficult to concentrate their attention on one thing, they quickly get tired and deviated. For this purpose, different developmental activities are done, tyflotechnical measures are taken to improve the writing difficulties with Braille system. The organization of the writing for preliminary schoolchildren who are blind and have residual vision with Braille system is carried out on the basis of hearing and touching, so it's very important to develop fine motor skills and tactile perception because it's impossible to feel the examined items without them (Davtyan, 2018).

Along with writing with Braille system, some work is carried out to improve children's' fine motor skills and micro spatial orientation.

It should be noted that during daily school activities, substantial work is being done to improve the writing skills of these children. While organizing teaching Braille, great attention was 
paid to the above-mentioned issues. And the majority of teachers have emphasized the effectiveness of using a "Study preparedness assessment form for preliminary school children who are blind and have residual vision".

\section{CONCLUSION}

The results of the study showed that teaching Braille literacy to schoolchildren who are blind or have residual vision during educational process is important because the base of educational process is the writing and an integral part of implementing it, is to do it correctly and objectively. However, in this regard appropriate methods and measures need to be completed. It is also explained by the absence of relevant scientific and methodological literature.

The studies show that teaching the writing to children with visual impairments during educational process needs to be replenished. It is the result of less mobility and activity, lack of interest, defective development of fine motor skills, lack of relevant books, and equipment. Our studies showed that teaching the writing plays an important role. That's why some measures and methods are taken and developing games are organized. This is explained by the lack of the necessary literature dedicated to the study problem, targeted work, and didactic materials for the transmission of visual knowledge. However, to carry out this work successfully there is a need to replenish research and cooperate.

\section{REFERENCE LIST}

1. Andjelkovic, M. (2017). Conceptual skills in persons with visual impairment, Specijalnaedukacijairehabilitacija (Beograd), Vol. 16, br. 1. 9-33.

2. Avramidis, E., \& Norwich, B. (2010). Teachers' attitudes towards integration/inclusion: Areview of literature'. European Journal of Special Needs Education, 17(2), 129-147.

3. Bardin, J. A., Lewis, S. (2008). A survey of the academic engagement of students with visualimpairment general education classes. Journal of Visual Impairment \& Blindness, 102(8),472-483.

4. Damon, R. (2012). Braille is spreading but who's using it?. BBC News. Retrieved 14 October 2013. 
5. Experts Gathering In Houston To Discuss How Braille Is Taught - And What It Can Teach Us. National Public Radio, 5 May 2018 "What is Braille". American Foundation for the Blind.

6. Seim E., C., Quigley, D., \& Starner, E., Th. (2014). Passive Haptic Learning of Typing Skills Facilitated by Wearable Computers. In CHI '14 Extended Abstracts on Human Factors in Computing Systems (CHI EA '14). ACM, New York, NY, USA, 2203--2208.

7. Davtyan, S. R. (2018). Tesoghutyan khangarum unecogh nakhadprocakanner itaracakan koghmnoroshman karoghutyunneri dzevavorman ev zargacman mijocnern yntaniqum (Assessment and Development of Spatial Orientation Skills of Preschoolers with Visual Impairment in the Family), Usumnametodakan dzernark, "Nahapet" hratarakchutyun, Yerevan, 47 ej

8. Hudson, L., J. (2012). I ntroducing Braille, Perkins School for the Blind, 93

9. Hermida, F.X., Rodríguez, C. A. (1996) . A Braille O.C.R. for Blind People, Proc. of ICSPAT, 5-7.

10. Seim, C., Estes, T., Starner, T. (2015). Towards Passive Haptic Learning of piano songs. In 2015 IEEE World Haptics Conference (WHC). 445-450 